Boise State University

ScholarWorks

$12-28-2017$

\title{
"The Devil is in the Details:" Inland Northwest Stakeholders' Views on Three Forest-Based Bioenergy Scenarios
}

Soren Newman

University of Idaho

Darin Saul

University of Idaho

Robert Keefe

University of Idaho

Ryan Jacobson

University of British Columbia

Tamara Laninga

Western Washington University

See next page for additional authors

\section{(c) (1) (9)}

This document was originally published in Forest Science by Society of American Foresters. This work is provided under a Creative Commons Attribution Non-Commercial license. Details regarding the use of this work can be found at: http://creativecommons.org/licenses/by-nc/4.0/. doi: 10.5849/FS-2016-083R1 


\section{Authors}

Soren Newman, Darin Saul, Robert Keefe, Ryan Jacobson, Tamara Laninga, and Jillian Moroney 


\title{
"The Devil Is in the Details:" Inland Northwest Stakeholders' Views on Three Forest-Based Bioenergy Scenarios
}

\author{
Soren Newman, Darin Saul, Robert Keefe, Ryan Jacobson, Tamara Laninga, and Jillian Moroney
}

Public and private initiatives are actively exploring a range of forest-based bioenergy development options in the Inland Northwest of the United States. These efforts are motivated in part by the potential to generate renewable energy while creating a market for forest residues that would facilitate hazardous fuels reduction and provide economic opportunities. Understanding stakeholders' perspectives is critical to the feasibility and long-term viability of bioenergy projects. This study presents stakeholder perspectives on forest-based bioenergy development strategies for communities in the forested areas of Idaho, western Montana, eastern Washington, and eastern Oregon. We developed three scenarios based on bioenergy initiatives currently being explored in the region: a decentralized mobile biochar and drop-in fuel scenario, a centralized bioaviation fuel scenario, and a centralized wood pellet scenario. We then asked a range of stakeholders to identify and assess the tradeoffs they associated with each scenario during in-depth interviews. Participants were generally supportive of any viable scenario that supports forest restoration and economic development, but many favored small-scale, locally oriented bioenergy development similar to what has occurred in some rural communities related to local food systems.

Keywords: local products, biomass, wood pellets, biofuel, public acceptance

T The US Inland Northwest (INW) includes the Interior Columbia River Basin spanning Oregon and Washington from east of the Cascade Mountains across northern Idaho to the Continental Divide in western Montana (Hessburg and Agee 2003). The region has the potential to support a bioenergy industry using its abundant forest biomass resources. Forest-based bioenergy development could produce renewable energy, reduce slash burning and wildfire risk, and provide economic development opportunities (Cambero and Sowlati 2014, Gan and Smith 2007).

Although abundant forest biomass exists in the INW region, large portions are currently unavailable because it is uneconomic to harvest and transport. The forest products industry is a dominant economic sector in the INW that could support bioenergy development by colocating processing (van Heiningen 2006), but it could also compete for feedstock. To be successful, a forest-based bioenergy system in the INW will need to adapt to the local circumstances necessary for a reliable feedstock supply.

Bioenergy is not new in the region. Forest residues are used to produce wood pellets, heat individual houses, and in small com- bined heat and power generators. Recently, considerable investment in development of biobased transportation fuels has occurred. In 2011, the US Department of Agriculture National Institute of Food and Agriculture (NIFA) awarded a large grant to the Northwest Advanced Renewables Alliance (NARA) to develop and pilot a regional-scale, forest-based bioaviation fuel system (NARA 2016). In 2013, the agency awarded a grant to the Bioenergy Alliance Network of the Rockies (BANR) to advance modular thermochemical conversion technologies to produce liquid biofuel and biochar on site, particularly using beetle-killed timber as feedstock (BANR 2015).

As initiatives like these unfold, including the perspectives of stakeholders - those who directly influence or are affected by a decision (Freeman 2010) — will improve project viability and distribution of benefits (Bailey et al. 2011, Marciano et al. 2014). However, most forest-based bioenergy literature has focused on technological, economic, or environmental aspects, with fewer studies considering social contexts (Cambero and Sowlati 2014). Much of the sociological literature draws on general public surveys because public

Manuscript received September 6, 2016; accepted May 5, 2017; published online June 15, 2017.

Affiliations: Soren Newman (newman@uidaho.edu), College of Agricultural and Life Sciences, University of Idaho, 875 Perimeter Drive MS 2331, Moscow, ID 83844.DarinSaul(dsaul@uidaho.edu), College of Agricultural and Life Sciences, University of Idaho. Robert Keefe (robk@uidaho.edu),Department of Forest, Rangeland and Fire Science, College of Natural Resources, University of Idaho. Ryan Jacobson (rjacobso1988@gmail.com), Department of Chemical and Biological Engineering, University of British Columbia. Tamara Laninga (tamara.laninga@wwu.edu), Environmental Studies Department, Huxley College of the Environment, Western Washington University. Jillian Moroney (jillianmoroney@boisestate.edu), School of Public Policy, Boise State University.

Acknowledgments: We gratefully acknowledge support from USDA-AFRI (grant number 2012-00948). We also thank Christy Dearien, Debbie Gray, Tenley Burke, Erinn Cruz, and Priscilla Salant for their contributions to the project. 
perceptions and acceptance affect the feasibility of bioenergy projects (Halder et al. 2012, Plate et al. 2010). Local environmental impacts, local benefits, developer credibility, familiarity with the technology, and opportunities to influence the process are among the factors found to influence public perceptions (Eswarlal et al. 2014, Upreti 2004). Some studies have documented greater public acceptance for small-scale bioenergy projects, which are understood as less controversial and more likely to advance forest health and local communities' goals (Madlener and Vögtli 2008, Nuss 2014).

Forest bioenergy stakeholders hold diverse values, interests, and goals that can vary by group, level of project involvement, and geographic location (Dwivedi and Alavalapati 2009, Johnson et al. 2013). This study builds on the literature examining expert and engaged stakeholder perspectives and insights. Many of these studies are in the US Southeast, where a large proportion of forested lands are privately owned (Bailey et al. 2011, Mayfield et al. 2007); other countries (MacGregor et al. 2014); or where public lands are involved (Becker et al. 2011, Stidham and Simon-Brown 2011). Stidham and Simon-Brown (2011) interviewed Oregon stakeholders in 2006, finding widespread support for forest-based energy development. Few other studies have explored the social dynamics of bioenergy development from the perspective of engaged stakeholders in the US Northwest, and no study to our knowledge has focused on the INW.

Whereas much of the sociological bioenergy literature focuses on general public perceptions, acceptability of specific technologies (Tagashira and Senda 2011), or forest-based bioenergy development in general (Dwivedi and Alavalapati 2009), this study conducted in-depth interviews with engaged stakeholders to explore trade-offs of three current strategies. We explore the following question: Of the proposed forest-based bioenergy alternatives, what would those most likely to be directly involved and affected prefer to see happen and why? This research helps anchor development planning in the experience and needs of those living and working in the affected area.

\section{Methods}

\section{Study Region}

Our study region covers the forested areas of northern and central Idaho, northeastern Oregon, eastern Washington, and western Montana (Figure 1). Approximately half (51\%) of the forested land in this area is privately owned, $46 \%$ is US Forest Service land, and $3 \%$ is owned by the Idaho Department of Lands (Conservation Biology Institute 2012, Fry et al. 2011). We chose this area because of its economic and ecological coherence and differences relative to the rest of the US Northwest, its well-developed forest products industry, and the extensive analyses underway for uses of its forest biomass.

Compared with the forests of western Washington and Oregon, INW forests are more prone to fire and are slower growing. With an average of 26 people per square mile, the study region is very rural, with lower population densities in counties with higher percentages of timberland: counties with $91 \%$ or more timberland have only 5 people per square mile (US Census Bureau 2014a, 2014b). Since 2000 , population growth in the study region has been slower than in three of the four states of which they are part: there was $17 \%$ population growth in the study region between 2000 and 2016 compared with 30\% in Idaho, 16\% in Montana, 20\% in Oregon, and $24 \%$ in Washington (US Census Bureau 2016). Unemployment rates in the study region are generally higher than the national rate, especially in counties with $91 \%$ or more timberland, where the rate peaked after the latest economic recession at 14\% in 2009 (US Bureau of Labor Statistics 2014).

\section{Scenario Development}

Our research objectives were twofold: to understand stakeholders' perspectives on bioenergy development in the INW (reported here) and to help define realistic scenarios for a broader multidisciplinary project (Jacobson et al., 2016; Kosse et al., 2016). We started with two scenarios based on options being explored by NARA and BANR. In May 2013, we met with forestry stakeholders in Moscow, ID, to assess interest in the scenarios. Participants included multistate managers for the two largest corporate timberland owners in the region, a tribal land manager, the director of the regional logging contractors association, and the principal investigator from NARA. Participants affirmed interest in the regional bioaviation fuel scenario and a smaller-scale, decentralized approach, and they helped refine these scenarios for our analyses. Participants also identified wood pellet production for Asian markets as a third scenario of interest.

The scenarios were further refined with our 16-member project advisory committee, which included economic development professionals, forest and energy industry representatives, conservation group representatives, natural resource managers, and researchers. Table 1 summarizes the resulting scenarios.

\section{Stakeholder Interviews}

We conducted semistructured interviews in fall 2013 with representatives of forest industry, conservation and environmental nongovernmental organizations (ENGOs), city and county governments, state and federal land management agencies, tribes, economic development organizations, nonindustrial private forestland (NIPF) owners, and other key informants for a total of 45 interviews involving 48 participants (Table 2 ). Although our sample primarily included key informants with firsthand knowledge of forest-based bioenergy issues, participants were identified through purposive and snowball sampling to include a range of perspectives, knowledge,

\section{Management and Policy Implications}

Policy-makers, land managers, and foresters should be aware that the public generally supports bioenergy development that can help improve forest health and provide economic benefits to rural economies. However, stakeholders tend to favor bioenergy development options that are scaled in ways that result in economic benefits to local communities and include detailed project planning at local levels. For example, ENGOs expressed concerns about the details associated with road location, wildlife habitat conservation, and forest connectivity at the project scale while being generally supportive of bioenergy development overall. Similarly, many stakeholders feel that the financial benefits of larger-sized facilities, such as a regional biojet fuel refinery using more than 700,000 bone dry tons (BDT) of wood-based biomass annually, would be felt primarily by one or two large companies rather than providing benefits to the communities where forest resources are located. Among two biofuel and one wood pellet development scenarios considered, some stakeholders preferred wood pellet production because it is a simple and proven technology with existing markets. When working with forest collaboratives and coalitions, foresters and managers should focus on projects that highlight restoration, jobs, and other economic benefits locally to build broad support. 


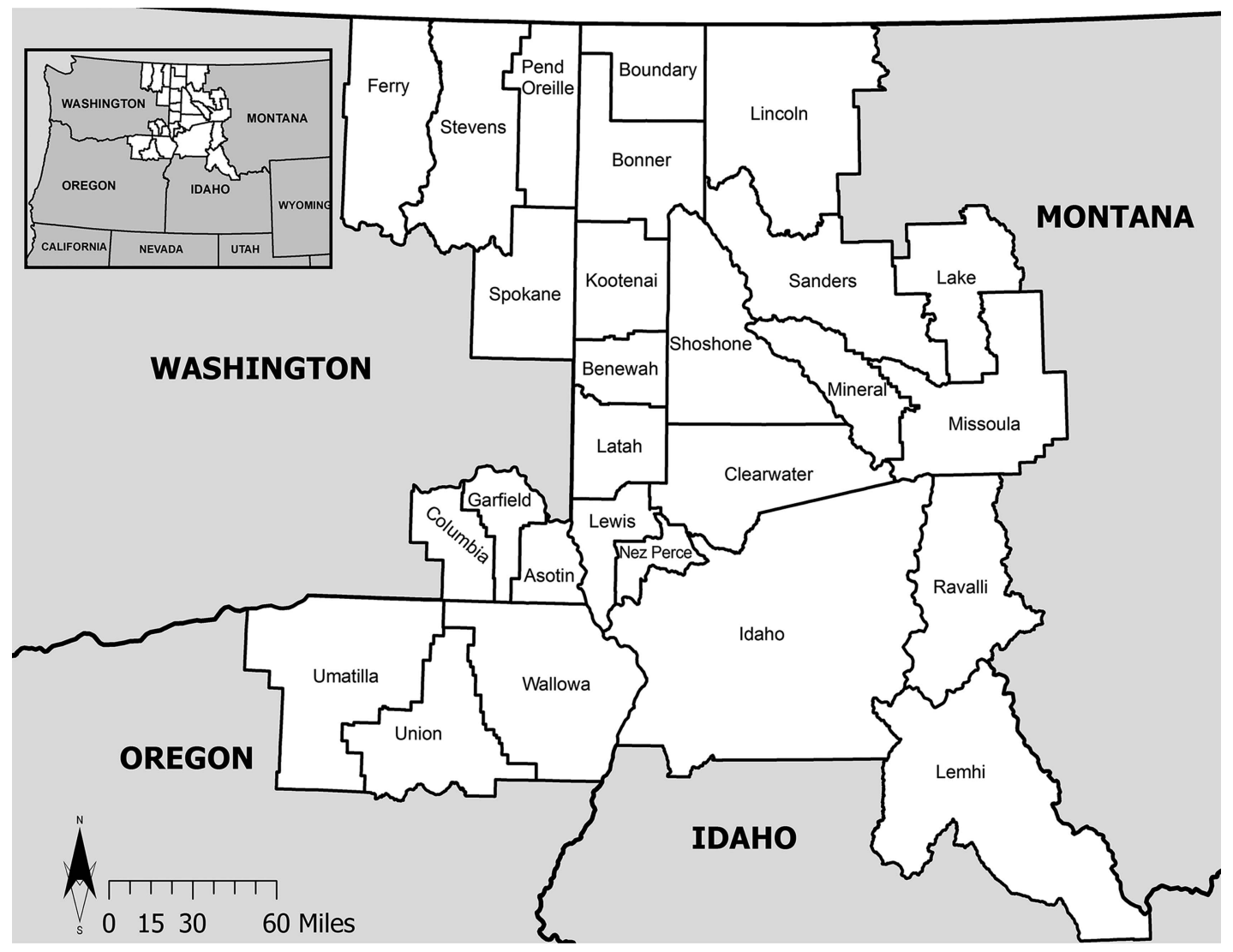

Figure 1. Study area.

Table 1. Scenario descriptions.

\begin{tabular}{|c|c|}
\hline Scenario & Description \\
\hline $\begin{array}{l}\text { S1: Decentralized biochar and } \\
\text { drop-in fuel production }\end{array}$ & $\begin{array}{l}\text { Forest biomass is used to produce drop-in fuel (similar to diesel, gasoline, or jet fuel and ready to "drop-in" to existing infrastructure) } \\
\text { and biochar (a charcoal byproduct that captures and stores } \mathrm{CO}_{2} \text { and can be used as an agricultural soil amendment). Gasoline and } \\
\text { biochar will be produced at small-scale, } 200,000 \mathrm{BDT} / \mathrm{yr} \text { mobile conversion stations located near areas that have high production } \\
\text { of chips and hog fuel (an unprocessed mix of coarse chips of bark and wood fiber) from logging residues, small-diameter trees, and } \\
\text { beetle-killed timber. Chips and hog fuel processed within stands or at log landings will be transported directly to the conversion } \\
\text { unit sites without further intermediate processing. Biofuel and biochar products will be transported by truck or rail to their end } \\
\text { use location. }\end{array}$ \\
\hline $\begin{array}{l}\text { S2: Centralized bioaviation } \\
\text { fuel production }\end{array}$ & $\begin{array}{l}\text { Forest biomass in the form of chips or hog fuel from commercial logging residues and small-diameter trees removed in thinning } \\
\text { operations are transported to a single, very large, regionally located bioaviation fuel facility }(>700,000 \mathrm{BDT} / \mathrm{yr}) \text {. This scenario } \\
\text { includes the possible use of intermediate preprocessing plants, or depots, where chips and hog fuel are upgraded to wood pellets to } \\
\text { increase the cost-effective transportation distance of feedstock materials for a regional biofuels facility. For example, chips and hog } \\
\text { fuel might be turned into pellets at a small pellet facility located at a log yard in Headquarters, ID, or in Clarkia, ID, before } \\
\text { transport to a large biofuels facility in Colville, WA. }\end{array}$ \\
\hline $\begin{array}{l}\text { S3: Centralized wood pellet } \\
\text { production }\end{array}$ & $\begin{array}{l}\text { Forest biomass in the form of chips or hog fuel from commercial logging slash (e.g., tree limbs, tree tops, and brush) and small- } \\
\text { diameter trees removed in thinning operations is transported directly to a wood pellet manufacturing facility ( } 300,000 \mathrm{BDT} / \mathrm{yr}) \text { in } \\
\text { the INW region. For example, Colville, WA; Lewiston, ID; and St. Maries, ID; will be considered as pellet facility locations in our } \\
\text { models. Wood pellets will be shipped via truck, rail, or barge to coastal ports and subsequently to Asian markets. This scenario is } \\
\text { modeled after similar, high-production pellet facilities in the US Southeast and Vancouver, BC. }\end{array}$ \\
\hline
\end{tabular}

and experience. Our sample included two project advisory committee members.

Interview questions were open ended to elicit in-depth and potentially unanticipated information. First, we asked for perspectives on general forest-based bioenergy opportunities, concerns, and obstacles. We then described and answered questions about the three scenarios from Table 1 and asked them to share their perspectives on the potential trade-offs, obstacles, desirability, and feasibility of each. Participants were able to refer to a handout during the interview and had received information about the project, including the scenarios, several days in advance. The phrasing of questions in this section referred to the INW as a whole, although many participants responded with their own community in mind.

Interviews lasted 45-90 min and were audio recorded and transcribed. We used ATLAS.ti qualitative data analysis software to analyze the data, which involved coding segments of data and organizing them into inductive categories (Charmaz 2006). We used an independent parallel coding procedure in which two researchers independently coded the first ten transcripts then compared their preliminary sets of codes and categories to assess and improve the trustworthiness of the analysis (Thomas 2006). The two sets were merged into a single analytical frame, which was further refined as 
Table 2. State and stakeholder group representation of participants.

\begin{tabular}{lr}
\multicolumn{1}{c}{ Characteristic } & Total \\
\hline State & \\
Idaho & 17 \\
Oregon & 12 \\
Washington & 6 \\
Montana & 13 \\
Total & 48 \\
Stakeholder group & \\
Forest industry & 4 \\
Conservation/ENGO & 7 \\
Local government & 4 \\
State/federal land management & 4 \\
Tribe & 7 \\
Economic development & 6 \\
Family/NIPF owners & 10 \\
Other key informants & 6 \\
Total & 48 \\
\hline
\end{tabular}

the primary researcher continued gathering and analyzing data iteratively until no new insights were forthcoming (i.e., data saturation; Richie et al. 2013). To further ensure trustworthiness, interview findings were discussed with our broader multidisciplinary research team and at a project advisory committee meeting.

\section{Results}

\section{General Opportunities, Concerns, and Obstacles}

Most participants ranged from being cautiously to enthusiastically supportive of using INW forest biomass to produce energy: "I think everything we can do to promote development of renewable energy is very important for the future of our planet" (Tribe). However, they typically predicated support on the development specifics:

The devil is in the details: what about the roads? What about the old-growth? What about the water quality? What about the habitat? Where are we leaving other types of forests to create a denser continuity across the landscape? (ENGO)

Participants' emphasis on local-level environmental issues and economic development stood out across most interviews regardless of stakeholder group: "It kills two birds with one stone-it helps forest health and the community be more economically and ecologically sustainable" (ENGO). Table 3 summarizes the most salient themes from the first section of the interview.

\section{Scenario Perspectives}

\section{Scenario 1: Decentralized Biochar and Drop-In Fuel Production}

To describe anticipated benefits of Scenario 1 (S1), many participants highlighted potential merits of drop-in fuel and biochar coproducts. For example, some liked the idea of locally sourced biofuel to "get away from the oil industry" (Forest industry) and that biochar could be used locally to improve soils. Although several participants observed that $S 1$ may be too small to enable significant forest restoration or economic development, the majority cited forest management potential as a primary benefit: "[The main benefit] goes back to managing the forest, hazardous fuel reduction, and getting some small-diameter wood out of the forest" (Tribe). Some participants thought $S 1$ would provide the greatest localized economic benefit: "I think one of the benefits ... is you get more local labor force involved .... So that would disperse the money back out to these rural areas" (Land manager).

Many participants liked that a value-added product is created on location rather than shipping raw materials to a regional facility, keeping the processing jobs close to the community, and reducing environmental and transportation costs. Several participants described $S 1$ as most likely to provide local ownership opportunities ("The first thing I would like would be local ownership and local production" [NIPF]) and be most responsive to local concerns and forest conditions.

One participant suggested that the small-scale, locally oriented supply chain could be leveraged as a marketing strategy:

It's using something that's local and creating a local product that would boost the local economy and you could market and advertise it as-you know, there's a lot of this "in your backyard," "grow your own food," "locavore-type" stuff going on. (ENGO)

Many also thought $S 1$ would garner the most public support:

You could get a lot of local support for it. A place like [this] where people see bug-killed trees, and ... biomass on the ground ... to say "hey, there's a facility right here that converts that to drop-in fuels."... It'd be easier to get support from even elected officials if it's benefiting folks right here locally. (ENGO)

Although the majority generally focused on the benefits of $S 1$, concerns included more roads on forested lands, concentrated overharvesting, a lack of investors from INW communities, and that mobile stations would not support stable jobs. The concern participants mentioned most frequently was related to fuel containment:

If you're doing that processing at the landing you're ... talking about impacts to the water and fish passage. If you're transporting ... by truck or rail you have all of those issues in terms of safety, environmental protections, secondary containment. (Tribe)

Participants primarily identified transportation economics, insufficient biochar markets, and insufficient and inconsistent supply of biomass as constraints.

\section{Scenario 2: Centralized Bioaviation Fuel Production}

The primary benefit attributed to the bioaviation fuel scenario (Scenario 2 [S2]) is its potential to enable large-scale forest management with significant environmental and economic benefits. If concerns about overharvesting are addressed, then most participants thought a greater forest restoration potential exists in a scenario at this scale. Several participants talked about the potential benefits of building a large-scale market for forest residues that facilitates forest management: "We'd be getting more [income] for the material so our costs per acre for treatments would go down, we could be treating more acres, employing more people, and a healthier forest" (Tribe).

The scale of S2 also seemed likely to some participants to create a substantial number of jobs. A few participants thought these jobs would be more stable than those created by S1: "The sustainability of those jobs [is a benefit] because if they're going to come in with a large plant ... they're going to be here for a long time" (Forest industry). A small number were optimistic that processing would be located in their area: "The project could provide over 100 jobs if we were able to become one of the conversion facility sites" (Economic development).

At the same time, a concern about S2 was that it would minimally benefit or even exploit INW communities by limiting their involvement to harvesting and shipping the material: "It's just like any mega development - the people that are providing the raw material get the shortest end of the stick" (Economic development). As 
Table 3. Summary of participants' perspectives on primary opportunities, concerns, and obstacles for INW forest-based bioenergy development.

\begin{tabular}{|c|c|c|}
\hline Perspective & Themes & Quotations \\
\hline \multirow[t]{7}{*}{ Opportunities } & Management to support forest health & My interest [is]...how it might be a tool to improve forest health. (ENGO) \\
\hline & Local economic development & An important benefit is the potential for local employment. (Other key informant) \\
\hline & Forest biomass market development & We generate a lot of woody material that doesn't have a market right now. (Tribe) \\
\hline & Reduce slash burning/improve air quality & Why not use it for something useful rather than burning and having it up in the air? (NIPF) \\
\hline & Reduce wildfire risk & It [could] help maintain a healthy forest and thereby decrease fire danger. (NIPF) \\
\hline & Use woody biomass resource & There's an untapped resource that's not being utilized. (Public land manager) \\
\hline & Reduce dependence on fossil fuels/foreign oil & We very much need to get off the dependency on natural gas, oil, and coal. (Public land manager) \\
\hline \multirow[t]{5}{*}{ Concerns } & $\begin{array}{l}\text { Overharvest/need for forest type-specific } \\
\text { management }\end{array}$ & $\begin{array}{l}\text { [My concern is the] inability to meet demand without overexploiting the resource. (Other key } \\
\text { informant) }\end{array}$ \\
\hline & $\begin{array}{l}\text { Exporting resources/wealth out of } \\
\text { communities }\end{array}$ & I would hate to think that the real wealth was being exported out of our region. (Tribe) \\
\hline & $\begin{array}{l}\text { Diminished air quality due to processing/ } \\
\text { manufacturing }\end{array}$ & If we develop [a facility] here, would it be able to meet air quality standards? (Tribe) \\
\hline & Soil, water, and wildlife-related impacts & Some see a dead tree in the forest as going to waste, [but it] is valuable for wildlife. (ENGO) \\
\hline & Distrust of large corporations & Big industry can [mislead] locals under the guise of an economic driver. (Economic development) \\
\hline \multirow[t]{7}{*}{ Obstacles } & Biomass supply from federal land & It's hard for the Forest Service to just jump in. (Other key informant) \\
\hline & Biomass supply from private land & Competition for biomass is going to be tremendous. [Mills] are using that product. (Forest industry) \\
\hline & Access to forest biomass & How do you accumulate the biomass and get it somewhere? (Public land manager) \\
\hline & Economics/expenses & The expense of...getting equipment to woody debris and [the biomass] to processing. (NIPF) \\
\hline & Public/ENGO support & $\begin{array}{l}\text { Extreme environmental groups who don't want to see any [forest] management [are an obstacle]. } \\
\text { (ENGO) }\end{array}$ \\
\hline & $\begin{array}{l}\text { Available timber industry infrastructure/ } \\
\text { workforce }\end{array}$ & Workforce availability is dwindling quite a bit. (Tribe) \\
\hline & $\begin{array}{l}\text { Forest-based bioenergy is more expensive } \\
\text { than other energy options }\end{array}$ & In this region we have such low electric rates with hydropower. (Economic development) \\
\hline
\end{tabular}

another example, two participants interviewed together discussed the potential of shipping biomass away from their community for processing at a centralized facility:

Participant 1. It might be profitable to somebody, but it isn't going to be profitable to the people at the local level. (Economic development)

Participant 2. I think communities like [ours] operate very much like third-world countries where we are used to taking our raw commodity and shipping it to someplace else for them to do a value-added product .... We don't want to be an underdeveloped county anymore. (ENGO)

Some thought jobs may be added at the regional level, but INW communities would only marginally benefit: "This isn't necessarily making jobs in the communities - it does add some, but when you ship things away, you ship things away" (NIPF).

Many participants also expressed concern that S2 may primarily benefit corporations from outside of the community: "History tells me that when you're dealing with big corporations ... they're the one that's going to make the money" (Forest industry). Some of these participants suggested that large corporations would incite public mistrust and be less likely to produce bioenergy in a socially and environmentally sustainable way than actors based in the region.

In addition to the potential for opposition, the most commonly identified constraints included transportation ("I would be concerned about transportation costs and the effect that transportation would have on the highways and freeways" [Local government]) and supply ("There are very few areas that will produce 770,000 bone dry tons in a geographical region that makes sense" [Tribe]). Some participants anticipated that S2 would require biomass from public lands. Many felt that any scenario that requires a significant, consistent supply of biomass from federal lands would likely fail.

\section{Scenario 3: Centralized Wood Pellet Production}

The most often identified benefit for the wood pellet scenario (S3) was that proven technology and markets exist: "There is a real market for it right now" (Land manager). Some identified international pellet markets as stronger than local markets: "International markets ... might be the only thing that's going to keep a community alive because there isn't ... a healthy domestic market" (Land manager). Many also liked S3's renewable energy benefits as a coal substitute in Asian power plants: "The main benefit ... is perhaps there's more of an emissions improvement ... substituting wood for coal than there would be for jet fuel" (ENGO).

Most participants saw S3 positively in terms of forest management and job creation. Participants compared its potential economic and forest management impacts to those possible under S2: "I think you're going to see [the bioaviation fuel and pellet scenarios] are going to create ... more jobs [than the drop-in fuel/biochar scenario]" (Elected official). However, similar to S1, some participants thought S3 would be more likely to localize benefits than S2. For example, some participants thought S3 would be likely to help sustain the existing industry ("The upside is that if local mills are looking at it, then it will continue to support the infrastructure we already have" [NIPF]) and create local jobs: "[The pellet scenario] positively creates jobs ... in the forest locally" (ENGO). As with S1, the preference for a "local" focus emerged as a theme:

Schumacher said "small is beautiful.”... Local first, regional second. If we're going to do something either regionally or internationally, does it make sense to the people who are going to be affected the most? (Tribe)

Although some thought that S3 would have local benefits, other participants felt most benefits would be concentrated wherever the 
Table 4. Summary of participants' assessment of scenario trade-offs.

\begin{tabular}{|c|c|c|c|}
\hline Potentialities & $\begin{array}{l}\text { S1: Decentralized biochar and drop-in fuel } \\
\text { production }\end{array}$ & $\begin{array}{l}\text { S2: Centralized bioaviation fuel } \\
\text { production }\end{array}$ & S3: Centralized wood pellet production \\
\hline Positives & $\begin{array}{l}\text { - Biochar and drop-in fuel products } \\
\text { - Greatest potential to secure public/ENGO } \\
\text { support } \\
\text { - Relatively small impact regionally, but significant } \\
\text { local-level economic and forest restoration } \\
\text { impacts } \\
\text { - Scalable and mobile } \\
\text { - Reduces transportation costs } \\
\text { - Potential for local ownership models }\end{array}$ & $\begin{array}{l}\text { - Large-scale economic development/job } \\
\text { creation potential } \\
\text { - Large-scale forest restoration potential } \\
\text { - Create a significant market for forest } \\
\text { biomass }\end{array}$ & $\begin{array}{l}\text { - Proven pellet market exists } \\
\text { - Renewable energy } \\
\text { - Reduction in greenhouse gas emissions by } \\
\text { replacing coal in Asian markets } \\
\text { - Job creation regionally } \\
\text { - Support existing forest industry infrastructure }\end{array}$ \\
\hline Negatives & $\begin{array}{l}\text { - Fuel production risks (e.g., pollution) } \\
\text { - Limited forest management and economic } \\
\text { development potential }\end{array}$ & $\begin{array}{l}\text { - Primarily benefits large corporations } \\
\text { - Small landowners/ communities limited } \\
\text { ability/opportunity to participate } \\
\text { - Manufacturing plant pollution }\end{array}$ & $\begin{array}{l}\text { - Economic benefits concentrated around } \\
\text { manufacturing area } \\
\text { - International market instead of domestic } \\
\text { - Transportation emissions }\end{array}$ \\
\hline Constraints & $\begin{array}{l}\text { - Transportation costs } \\
\text { - Biochar market } \\
\text { - Consistent/sufficient local supply }\end{array}$ & $\begin{array}{l}\text { - Transportation costs } \\
\text { - Consistent/sufficient supply } \\
\text { - Public/ENGO support }\end{array}$ & $\begin{array}{l}\text { - Transportation costs } \\
\text { - Feedstock quality }\end{array}$ \\
\hline
\end{tabular}

Table 5. Number of participants who identified each scenario as the "most desirable" by stakeholder group.

\begin{tabular}{lcccc}
\hline \multicolumn{1}{c}{ Stakeholder group } & $\begin{array}{c}\text { Decentralized biochar } \\
\text { and drop-in fuel (S1) }\end{array}$ & $\begin{array}{c}\text { Centralized } \\
\text { bioaviation fuel (S2) }\end{array}$ & $\begin{array}{c}\text { Centralized wood } \\
\text { pellet scenario (S3) }\end{array}$ & $\begin{array}{c}\text { Other small-scale, } \\
\text { local options }\end{array}$ \\
\hline Forest industry & 2 & 0 & 0 & 0 \\
Conservation/ENGO & 3 & 0 & 0 & 2 \\
Local government & 3 & 1 & 0 & 5 \\
State/federal land management & 1 & 0 & 0 & 0 \\
Tribe & 6 & 0 & 1 & 2 \\
Economic development & 2 & 0 & 0 & 3 \\
Family/NIPF owners & 6 & 2 & 2 & 5 \\
Other key informants & 3 & 0 & 0 & 5 \\
Total & 26 & 3 & 3 & 10 \\
\hline
\end{tabular}

pellets are processed: "It'd be similar to [the bioaviation fuel] scenario as far as jobs.... The jobs most likely are somewhere else where they're making the larger pellets" (Tribe).

Identified constraints included transportation costs and doubt that pellets produced from residues would be "clean" enough to burn in electricity-producing plants. A couple of participants thought pellet production would lack public support, depending on the scale: "I think [the pellet scenario] starts to get removed from people and I just wonder if you'd have less local support ... because people wouldn't necessarily think it's benefiting people in their own backyard" (ENGO). Table 4 summarizes the trade-offs participants associated with the scenarios.

\section{The Most "Desirable" Scenario}

Twenty-six participants identified S1 as the "most desirable" scenario for the INW. The second most-identified preference was for small-scale, locally oriented options outside of the three scenarios we presented (e.g., heating districts; Table 5). Several participants preferred development led by locally or regionally based companies, which they thought were more socially and environmentally sustainable, trustworthy, personally invested, and likely to secure public support. Although many participants said they prefer decentralized, locally or regionally based development, many also stated that ownership needs to be scaled so that key players are able to sustain the project. Although participants tended to prefer locally focused development, many said they would accept any scenario that could "get off the ground" (Economic development) if it promoted forest health.

\section{Discussion and Conclusions}

Although current initiatives focus on large-scale, regional systems, many stakeholders preferred development be as local as possible, including product end use, employment and ownership opportunities, and infrastructure development. What many participants hoped for is the type of small-scale economic development associated with local foods, which provide opportunities at individual and community levels for additional income and security. Often bootstrapped by individuals, families, and small retail organizations such as restaurants, cooperatives, and farmers' markets, this type of development relies on local support and local capital.

Some participants feared that regional-scale scenarios would continue a pattern of exporting raw materials and economic opportunities away from rural INW communities. And some worried that regional-scale development would lead to overharvesting. At the same time, many recognized that smaller, decentralized development might not provide significant economic or environmental benefits.

Many viewed the simple, proven pellet technology as an important benefit. Pellet mill technology can provide local jobs and value-added products at scales appropriate to forest health and restoration. Increased wood pellet infrastructure could also more efficiently provide feedstock to a future regional liquid biofuel facility at reduced costs relative to nonpelletized biomass (Keefe et al. 2014).

Some tension exists between the preference to maintain local control and benefits of the forest bioenergy system and support of any viable biofuel development. Although many thought that locally owned, more decentralized strategies would be best, many 
doubt this will occur or that what the locals want or need will be considered important. However, if bioenergy projects are perceived as exploiting communities' resources without promoting forest health and community needs and values, then projects are less likely to be viable in the future.

\section{Literature Cited}

Bailey, C., J.F. Dyer, AND L. TeETER. 2011. Assessing the rural development potential of lignocellulosic biofuels in Alabama. Biomass Bioenergy. 35(4):1408-1417. doi:10.1016/j.biombioe.2010.11.033.

Becker, D.R., S.M. McCaffrey, D. Abbas, K.E. Halvorsen, P. Jakes, AND C. Moseley. 2011. Conventional wisdoms of woody biomass utilization on federal public lands. J. For. 109(4):208-218. http://www. ingentaconnect.com/content/saf/jof/2011/00000109/00000004/ art00006.

Bioenergy Alliance Network of THE Rockies. 2015. Bioenergy Alliance Network of the Rockies (BANR). Retrieved from http://banr. nrel.colostate.edu/.

Cambero, C., AND T. Sowlati. 2014. Assessment and optimization of forest biomass supply chains from economic, social and environmental perspectives-A review of literature. Renew. Sustainable Energy Rev. 36:62-73. doi:10.1016/j.rser.2014.04.041.

CHARMAZ, K. 2006. Constructing grounded theory: A practical guide through qualitative analysis, 1 st ed. Sage, Thousand Oaks, CA.

Conservation Biology Institute. 2012. PAD-US (CBI Edition) Version 2. Conservation Biology Institute, Corvallis, OR. http://consbio. org/products/projects/pad-us-cbi-edition.

DwIVEDI, P., AND J.R. AlavalaPATI. 2009. Stakeholders' perceptions on forest biomass-based bioenergy development in the southern US. Energy Policy. 37(5):1999-2007. doi:10.1016/j.enpol.2009.02.004.

Eswarlal, V.K., G. VasudeVan, P.K. Dey, And P. Vasudevan. 2014. Role of community acceptance in sustainable bioenergy projects in India. Energy Policy 73:333-343. doi:10.1016/j.enpol.2014.04.019.

FREEMAN, R.E. 2010. Strategic management: A stakeholder approach, 2nd ed. Cambridge University Press, New York.

Fry, J., G. Xian, S. Jin, J. Dewitz, C. Homer, L. Yang, C. Barnes, N. Herold, AND J. WiCKHAM. 2011. Completion of the 2006 National Land Cover Database for the Conterminous United States, Photogramm. Eng. Remote Sens., 77(9):858-864. https://pubs.er.usgs.gov/ publication/70034549.

GAN, J., AND C.T. SMITH. 2007. Co-benefits of utilizing logging residues for bioenergy production: The case for East Texas, USA. Biomass Bioenergy. 31(9):623-630. doi:10.1016/j.biombioe.2007.06.027.

Halder, P., P. Prokop, C.-Y, Chang, M. Usak, J. Pietarinen, S. Havu-NuUtinen, P. PelKonen, AND M. CAKIR. 2012. International survey on bioenergy knowledge, perceptions, and attitudes among young citizens. Bioenerg. Res. 5(1):247-261. doi:10.1007/s12155-0119121-y.

Hessburg, P.F., And J.K. AgeE. 2003. An environmental narrative of inland northwest United States forests, 1800-2000. For. Ecol. Manage. 178(1):23-59. doi:10.1016/S0378-1127(03)00052-5.

Jacobson, R.A., R.F. Keefe, A.M.S. Smith, S. Metlen, D.A. SAul, S.M. NEWMAN, T.J. LANINGA, AND D. InMAN. 2016. Multi-spatial analysis of forest residue utilization for bioenergy. Biofuel. Bioprod. Bior. 10(5):560-575. doi:10.1002/bbb.1659.

JOHnson, T.L., J.M. Bielicki, R.S. DODdER, M.R. Hilliard, P.O. KAPLAN, AND C.A. MiLLER. 2013. Advancing sustainable bioenergy: Evolving stakeholder interests and the relevance of research. Environ. Manage. 51(2):339-353. doi:10.1007/s00267-012-9884-8.
Keefe, R., N. Anderson, J. Hogland, And K. Muhlenfeld. 2014. Woody biomass logistics P. 251-279 in Cellulosic energy cropping systems, Karlen, D. (ed). John Wiley, West Sussex, United Kingdom.

Kosse, E., S. Devadoss, R. Jacobson, And R. Keefe. 2016. Alternative fuel production and distribution from woody biomass in the Inland Northwest: A profit analysis. Unpublished manuscript. Department of Agricultural Economics and Rural Sociology, University of Idaho, Moscow, ID.

MACGREgor, M., M. AdAMS, AND P. DuinKer. 2014. Woodland owners' attitudes towards energy from forest biomass in a carbon-intensive jurisdiction: Case study of Nova Scotia, Canada. Renewable Energy, 68:611-617. doi:10.1016/j.renene.2014.02.002.

Madlener, R., AND VöGTLI, S. 2008. Diffusion of bioenergy in urban areas: A socio-economic analysis of the Swiss wood-fired cogeneration plant in Basel. Biomass Bioenergy 32(9):815-828. doi:10.1016/j. biombioe.2008.01.006.

Marciano, J.A., R.J. Lilieholm, M.F. Teisl, J.E. Leahy, And B. NeuPANE. 2014. Factors affecting public support for forest-based biorefineries: A comparison of mill towns and the general public in Maine, USA. Energy Policy 75:301-311. doi:10.1016/j.enpol.2014.08.016.

Mayfield, C.A., C.D. Foster, C.T. Smith, J. Gan, and S. Fox. 2007. Opportunities, barriers, and strategies for forest bioenergy and bio-based product development in the Southern United States. Biomass Bioenergy 31(9):631-637. doi:10.1016/j.biombioe.2007.06.021.

Northwest Advanced Renewables Alliance. 2016. Northwest Advanced Renewables Alliance. Retrieved from https://nararenewables.org/.

Nuss, M. L. 2014. The "great hope": Bioenergy in eastern Oregon and its implications for dry forest restoration. Oregon State University, Corvallis, OR. Retrieved from http://ir.library.oregonstate.edu/xmlui/handle/ $1957 / 46832$.

Plate, R., M. Monroe, and A. Oxarart. 2010. Public perceptions of using woody biomass as a renewable energy source. J. Extens. 48(3):1-15. http://www.joe.org/joe/2010june/a7.php.

Ritchie, J., J. Lewis, C. MCNaughton Nicholls, and R. ORmston. 2013. Qualitative research practice: A guide for social science students and researchers, 2nd ed. Sage, Thousand Oaks, CA.

STIDHAM, M., AND SIMON-BROWN, V. 2011. Stakeholder perspectives on converting forest biomass to energy in Oregon, USA. Biomass Bioenergy. 35(1):203-213. doi:10.1016/j.biombioe.2010.08.014.

TAGASHIRA, N., AND Y. SENDA. 2011. What information should be provided in communications on biomass power generation? Appl. Energy. 88(7):2519-2529. doi:10.1016/j.apenergy.2011.01.020.

THOMAS, D.R. 2006. A general inductive approach for analyzing qualitative evaluation data. Am. J. Eval. 27(2):237-246. doi:10.1177/ 10982140052837.

UPRETI, B.R. 2004. Conflict over biomass energy development in the United Kingdom: some observations and lessons from England and Wales. Energy Policy 32(6):785-800. doi:10.1016/S0301-4215(02) 00342-7.

US BUREAU OF LABOR STATISTICS. 2014. Local area unemployment statistics. Retrieved from http://data.bls.gov/cgi-bin/dsrv?la.

US Census Bureau. 2014a. Population estimates program. Retrieved from http://factfinder2.census.gov.

US Census Bureau. 2014b. State and county QuickFacts. Retrieved from http://quickfacts.census.gov/qfd/index.html.

US Census Bureau. 2016. Population estimates program. Retrieved from http://factfinder.census.gov.

van Heiningen, A. 2006. Converting a kraft pulp mill into an integrated forest products bio-refinery. Pulp Pap-Canada 107(6):38-43. 